\title{
Influence of the Meal and Genotype of CYP2C19 on the Pharmacokinetics of Proton Pump Inhibitors in Healthy Japanese Subjects
}

\author{
Hirohiko Shinkai ${ }^{1}$, Tomoyuki Koike ${ }^{1 *}$, Miki Shimada ${ }^{2}$, Kenichiro Nakagawa ${ }^{1}$, Katsunori Iijima ${ }^{1}$, \\ Yotaro Matsumoto ${ }^{2}$, Masamitsu Maekawa ${ }^{2}$, Nariyasu Mano ${ }^{2}$, Tooru Shimosegawa ${ }^{1}$ \\ ${ }^{1}$ Division of Gastroenterology, Tohoku University Graduate School of Medicine, Sendai, Japan; ${ }^{2}$ Department of Pharmaceutical Sci- \\ ences, Tohoku University Hospital, Sendai, Japan. \\ Email: "tkoike@rd5.so-net.ne.jp
}

Received July $21^{\text {st }}, 2013$; revised August $22^{\text {nd }}, 2013$; accepted September $2^{\text {nd }}, 2013$

Copyright (C) 2013 Hirohiko Shinkai et al. This is an open access article distributed under the Creative Commons Attribution License, which permits unrestricted use, distribution, and reproduction in any medium, provided the original work is properly cited.

\begin{abstract}
Objectives: To evaluate the influence of meals on the pharmacokinetics of omeprazole and rabeprazole and to investigate these PPIs with reference to CYP2C19 genotypes in healthy Japanese men. Methods: This was a randomized, open label, four-way crossover study. Twelve healthy Japanese male volunteers received a single oral dose of either 20 $\mathrm{mg}$ omeprazole or $10 \mathrm{mg}$ rabeprazole, in the fasted state and after a standardized breakfast. Results: Between the administration of omeprazole in the fasted state and after breakfast, there were no significant differences in Cmax, AUC, Tmax, and half-life. Between the administration of rabeprazole in the fasted state and after breakfast, there were no significant differences in Cmax, AUC and half-life, whereas the Tmax of rabeprazole after breakfast was significantly delayed ( $2.8 \pm 1.0$ vs $5.3 \pm 1.8 \mathrm{~h}$, respectively; $\mathrm{p}=0.006$ ). PMs demonstrated the highest $\mathrm{Cmax}$ and AUC after drug intake under the fasting state and after breakfast, and homo EMs showed a significantly delayed Tmax. Conclusion: When a single dose of either PPI was administered, the pharmacokinetics of omeprazole was not affected by the meal, whereas the Tmax of rabeprazole after the meal was significantly delayed.
\end{abstract}

Keywords: Proton Pump Inhibitor; Omeprazole; Rabeprazole; CYP2C19; Pharmacokinetics

\section{Introduction}

Gastroesophageal reflux disease (GERD) is a common disease in Western countries [1-3], and the number of patients with GERD is increasing in Japan [4-7]. Gastric acid has an important role in the pathogenesis of GERD. The primary therapeutic approach is suppression of gastric acid secretion, and stronger and prompter gastric acid suppression is required [8]. Proton pump inhibitors (PPIs) are commonly used as first-line inhibitors because of the high effectiveness and prolonged duration of suppression of gastric acid secretion.

PPIs, such as omeprazole and rabeprazole, are absorbed in the small intestine and inhibit gastric acid secretion by selectively and non-competitively inactivating proton pump $\left(\mathrm{H}^{+}, \mathrm{K}^{+}\right.$ATPase $)$in gastric parietal cells $[9,10]$. Omeprazole is primarily metabolized by cytochrome P450, family 2 , subfamily C, and polypeptide 19

"Corresponding author.
(CYP2C19) and partially metabolized by CYP3A4 [1113]. Three CYP2C19 genotypes have been identified: homozygous extensive metabolizer (homo EM), heterozygous extensive metabolizer (hetero EM) and poor metabolizer (PM) $[12,13]$. Several studies have reported that the metabolism of omeprazole is influenced by the CYP2C19 genotype, resulting in interindividual variabilities in the pharmacokinetics and pharmacodynamics of omeprazole [11-13]. Accordingly, the genetic polymorphism of CYP2C19 should be of clinical concern in the treatment of acid-related diseases with proton pump inhibitors. On the other hand, rabeprazole is mainly degraded via a non-enzymatic pathway and is only partially metabolized by CYP2C19 and CYP3A4 [14-17].

Thus, rabeprazole is considered to be less affected by the CYP2C19 genotype status compared with other PPIs.

The acid-inhibitory effects of PPIs are significantly dependent on the genotype status, as well as on their intrinsic pharmacokinetic and pharmacodynamic charac- 
teristics and dosing schemes [10,17-20]. The effect of omeprazole on the suppression of gastric acid secretion was related to the area under the time-plasma concentration curve (AUC) [21,22]. In western countries, to avoid the influence of meals on the pharmacokinetics of PPIs, PPIs are usually administrated before a meal. But in Japan, many outpatients take many drugs. Hence, in order to improve drug compliance, omeprazole and rabeprazole are also generally administered after a meal with other drugs.

There are some studies that have shown no effect of food intake on the maximum plasma concentrations (Cmax) and AUC of omeprazole or rabeprazole [23,24].

But it is unclear that which PPI is less influenced by meals between omeprazole and rabeprazole. Therefore, we sought to compare the pharmacokinetics of omeprazole or rabeprazole between under a fasting condition and after breakfast. The objectives of this study were to evaluate the influence of meals on the pharmacokinetics of omeprazole and rabeprazole and to investigate these PPIs with reference to the CYP2C19 genotypes in healthy Japanese men.

\section{Materials and Methods}

This was a randomized, open label, four-way crossover study conducted in a single center in Japan. Omeprazole and rabeprazole are generally administered at doses of 20 $\mathrm{mg}$ or $10 \mathrm{mg}$, respectively, in the clinical setting in Japan. Thus, in the present study, the omeprazole and rabeprazole doses were set at $20 \mathrm{mg}$ and $10 \mathrm{mg}$, respectively.

\subsection{Subjects}

Twelve healthy Japanese male volunteers (mean age 28.5 \pm 7.0 years) were enrolled. The exclusion criteria included a history of hypersensitivity reactions to any PPI; a history of gastrointestinal disorders or surgery likely to influence drug absorption; a history of significant medical illness; a need to use any prescription or over-thecounter medications during the study.

\subsection{Cytochrome P450 (CYP) 2C19 Genotyping}

After obtaining informed consent, venous blood samples were collected from all participants. DNA was extracted from venous white blood cells. Genetic mutations were analyzed by fluorescence correlation spectroscopy [25]. On the basis of point mutations in exons 5 and 4, the CYP2C19 gene status can be classified as homo EM, hetero EM, or PM $[22,26,27]$. Homo EM has wild type (wt) alleles (wt/wt) without any mutation in exons 5 or 4 ; PM has $\mathrm{m} 1$ mutation $(\mathrm{m} 1)$ alleles or $\mathrm{m} 2$ mutation $(\mathrm{m} 2)$ alleles with mutations in both exons 5 and $4(\mathrm{~m} 1 / \mathrm{m} 2$, $\mathrm{m} 1 / \mathrm{m} 1$, or $\mathrm{m} 2 / \mathrm{m} 2$ ); and hetero EM has a mutated allele in either exon 5 or $4(\mathrm{wt} / \mathrm{m} 1$ or $\mathrm{wt} / \mathrm{m} 2)$.

\subsection{Study Protocols}

Each subject, after an overnight fast, received a single oral dose of either $20 \mathrm{mg}$ of omeprazole or $10 \mathrm{mg}$ of rabeprazole with $200 \mathrm{~mL}$ water at 8:00, in the fasted state or after a standardized breakfast in a randomized, crossover manner. Each study phase was followed by a washout period of at least 7 days. A standardized breakfast with 712 kilocalories was provided at 7:45. A standardized meal with 1080 kilocalories was provided at 12:30. The total nutrient content of the breakfast and lunch was $1792 \mathrm{kcal}$; protein, $42.8 \mathrm{~g}$ lipid, $115.4 \mathrm{~g}$ and glucose $145.4 \mathrm{~g}$. Venous blood samples to measure the plasma concentrations of either omeprazole or rabeprazole were collected before and 1, 1.5, 2, 3, 4, 5, 6, 7, and $10 \mathrm{~h}$ after dosing. These samples were separated by centrifugation at $3000 \mathrm{rpm}$ for $10 \mathrm{~min}$ and then were stored at $-20^{\circ} \mathrm{C}$ until analysis.

\subsection{Pharmacokinetic Assessments}

Blood samples were collected in heparinized tubes before and $0.5,1,1.5,2,3,4,5,6,7,10 \mathrm{~h}$ after the administration of each drug. The blood samples were immediately centrifuged at $3000 \mathrm{r} / \mathrm{min}$ for $10 \mathrm{~min}$. All samples were stored at $-20^{\circ} \mathrm{C}$ until assayed.

For the determination of the rabeprazole levels in plasma, $100 \mu \mathrm{L}$ of $1 \%$ diethylamine solution was added to $1 \mathrm{~mL}$ of plasma. The plasma levels of omeprazole and rabeprazole were measured by high-performance liquid chromatography assay (HPLC) method [26,27]. Analytes and the internal standard were separated using a mobile phase of acetonitrile $/ 1 \mathrm{mmol} / \mathrm{L}$ ammonium formate (140/ $60, \mathrm{v} / \mathrm{v})$ on a $\mathrm{C} 18$ analytical column and analyzed in the selected reaction-monitoring (SRM) mode. The lower limit of quantification was $500 \mathrm{fg} / 20 \mu \mathrm{L}$.

\subsection{Assay of OPZ, RPZ Concentration in Plasma}

$50 \mu \mathrm{L}$ of internal standard (IS) solution (lansoprazole dissolved in $0.1 \mathrm{~N} \mathrm{NaOH} \mathrm{aq}$ /methanol) was added to 200 $\mu \mathrm{L}$ of plasma. Omeprazole, rabeprozole, and IS in the plasma sample were twice extracted with $1 \mathrm{~mL}$ of $0.1 \%$ diethylamine in ethyl acetate. The mixture was vortexed and centrifuged at $4900 \mathrm{rpm}$ for $3 \mathrm{~min}$ and the organic phase was transferred into another tube and evaporated to dryness under a nitrogen stream. The residue was reconstituted in $100 \mu \mathrm{L}$ of $0.1 \mathrm{~N} \mathrm{NaOH}$ aq/methanol (70:30, v/v). $90 \mu \mathrm{L}$ aliquot was analyzed by HPLC (Prominence, Shimadzu Tokyo, Japan). 


\subsection{Statistical Analyses}

In this study, the necessary sample size was not calculated. The values are expressed as mean values \pm standard deviation. If at least three-ninths of the sampling schedule were quantifiable, the mean plasma concentrations were calculated. The statistical differences in pharmacokinetic findings of each PPIs, in the fasting state and without breakfast were evaluated using paired t-test. Comparisons of the parameters among the three CYP2C19 genotypes were conducted using one-way analysis of variance (ANOVA) with a Bonferroni correction. A p-value of $<0.05$ was considered to be statistically significant.

\subsection{Ethics}

The study was performed in accordance with the Declaration of Helsinki. The study protocol was approved by the ethics committee of the Tohoku University Graduate School. UMIN000004761 Subjects provided written informed consent before participating.

\section{Results}

Because of the low plasma concentrations, 3 subjects, 1 of whom received omeprazole and 2 who received rabeprazole after breakfast, were excluded from the analysis set. One subject whose plasma concentration of rabeprazole after breakfast was $0 \mathrm{ng} / \mathrm{ml}$ at every measurement time was included in the analysis.

A total of 9 subjects consisting of 3 PMs (33.3\%), 2 hetero EMs (22.3\%), and 4 homo EMs (44.4\%) were included in the pharmacokinetic analyses. The characteristics of the participants are shown in Table 1. Among the three CYP2C19 genotype groups, there were no significant differences in terms of subject profiles, including age, height, body weight, and body mass index (Table 2).

The median pharmacokinetic parameters of 9 subjects are shown in Table 3. The mean plasma concentrationtime curves of omeprazole and rabeprazole in fasting state and after breakfast are shown in Figure 1. Because at least three-ninths of the sampling schedule were not quantifiable, the $\mathrm{AUC}_{0 \text {-inf }}$ of omeprazole after breakfast was calculable by each of 8 subjects, and that of rabeprazole after breakfast was obtained in only each of 3 subjects. Therefore, the $\mathrm{AUC}_{0-\mathrm{t}}$, but not the $\mathrm{AUC}_{0 \text {-inf }}$ was evaluated. Between the administration of omeprazole in the fasted state and after breakfast, there were no significant differences in Cmax (666.7 \pm 587.0 vs $574.9 \pm 556.2$ $\mathrm{ng} / \mathrm{ml}$, respectively), $\mathrm{AUC}_{0-\mathrm{t}}(2143.6 \pm 2382.9$ vs 1511.1 $\pm 1677.5 \mathrm{ng} \cdot \mathrm{h} / \mathrm{mL}$, respectively), Tmax $(2.9 \pm 1.3 \mathrm{vs}$

Table 1. Baseline characteristics of study participants.

\begin{tabular}{lc}
\hline No. of subjects & 9 \\
\hline Age (years) & $28.7 \pm 8.0$ \\
Height $(\mathrm{cm})$ & $172.7 \pm 5.1$ \\
Body Weight $(\mathrm{kg})$ & $65.5 \pm 10.1$ \\
Body mass index $\left(\mathrm{kg} / \mathrm{cm}^{2}\right)$ & $21.9 \pm 2.8$ \\
\hline
\end{tabular}

Data represent mean values \pm standard deviation.

Table 2. Baseline characteristics of study participants with the different CYP2C19 genotypes.

\begin{tabular}{lccc}
\hline & & CYP2C19 genotype & PM \\
\cline { 2 - 4 } & Homo EM & Hetero EM & 3 \\
No. of subjects & 4 & 2 & $30.7 \pm 7.1$ \\
Age (years) & $24.8 \pm 5.9$ & $33.5 \pm 13.4$ & $170.0 \pm 5.6$ \\
Height $(\mathrm{cm})$ & $173.3 \pm 4.8$ & $175.5 \pm 6.4$ & $60.0 \pm 6.8$ \\
Body Weight $(\mathrm{kg})$ & $66.4 \pm 8.3$ & $72.5 \pm 17.7$ & $\mathrm{NS}$ \\
Body mass index $\left(\mathrm{kg} / \mathrm{cm}^{2}\right)$ & $20.6 \pm 1.5$ & $23.4 \pm 4.0$ & $22.2 \pm 3.3$ \\
\hline
\end{tabular}

NS, not significant; Data represent mean values \pm standard deviation; Homo EM, homozygous extensive metabolizer; Hetero EM, heterozygous extensive metabolizer; PM, poor metabolizer.

Table 3. Pharmacokinetic parameters of omeprazole and rabeprazole in fasted state and after a meal.

\begin{tabular}{|c|c|c|c|c|c|c|}
\hline \multirow{2}{*}{ Parameter } & \multicolumn{2}{|c|}{ Omeprazole (20 mg) } & \multirow[b]{2}{*}{ p-value } & \multicolumn{2}{|c|}{ Rabeprazole (10 mg) } & \multirow[b]{2}{*}{$\mathrm{p}$-value } \\
\hline & In fasted state & After a meal & & In fasted state & After a meal & \\
\hline $\mathrm{Cmax}(\mathrm{ng} / \mathrm{mL})$ & $666.7 \pm 587.0$ & $574.9 \pm 556.2$ & NS & $264.3 \pm 88.4$ & $189.1 \pm 170.2$ & NS \\
\hline $\mathrm{AUC}_{0-\mathrm{t}}(\mathrm{ng} \cdot \mathrm{h} / \mathrm{mL})$ & $2143.6 \pm 2382.9$ & $1511.1 \pm 1677.5$ & NS & $548.5 \pm 255.1$ & $480.6 \pm 434.6$ & NS \\
\hline $\operatorname{Tmax}(\mathrm{h})$ & $2.9 \pm 1.3$ & $4.1 \pm 1.9$ & NS & $2.8 \pm 1.0$ & $5.3 \pm 1.8$ & 0.01 \\
\hline $\mathrm{t} 1 / 2(\mathrm{~h})$ & $2.3 \pm 1.5$ & $1.5 \pm 0.8$ & NS & $1.6 \pm 1.5$ & $3.3 \pm 1.7$ & NS \\
\hline
\end{tabular}

NS, not significant; data represent mean values \pm standard deviation; Homo EM, homozygous extensive metabolizer; Hetero EM, heterozygous extensive metabolizer; $\mathrm{PM}$, poor metabolizer Camx, maximum plasma concentrations, $\mathrm{AUC}_{0-\mathrm{t}}$, the area under the plasma-time concentration curve, Tmax, the time to maximum plasma concentration from time 0 to the time of the last quantifiable concentration, $\mathrm{t} 1 / 2$, half-time. 
$4.1 \pm 1.9 \mathrm{~h}$, respectively) and half-life $(2.3 \pm 1.5$ vs $1.5 \pm$ $0.8 \mathrm{~h}$, respectively). Between the administration of rabeprazole in the fasted state and after breakfast, there were no significant differences in Cmax $(264.3 \pm 88.4$ vs $189.1 \pm 170.2 \mathrm{ng} / \mathrm{ml}$, respectively), $\mathrm{AUC}_{0-\mathrm{t}}(548.5 \pm$ 255.1 vs $480.6 \pm 434.6 \mathrm{ng} / \mathrm{ml}$, respectively), half-life (1.6 \pm 1.5 vs $3.3 \pm 1.7 \mathrm{~h}$, respectively), whereas the Tmax of rabeprazole after breakfast was significantly delayed in comparison to that in the fasted state $(2.8 \pm 1.0$ vs $5.3 \pm$ $1.8 \mathrm{~h}$, respectively; $\mathrm{p}<0.01$ ).

The pharmacokinetic parameters of omeprazole in the three different genotype groups following the administration of the respective PPI are shown in Table 4. The mean plasma concentration-time curves of omeprazole in the three different genotype groups are shown in Figure 2. In each CYP2C19 genotype, between the administration of omeprazole in the fasted state and after breakfast, there were no significant differences in $\mathrm{Cmax}$ and $\mathrm{AUC}_{0-\mathrm{t}}$. In hom Ms, the Tmax of omeprazole after breakfast tended to be delayed, although the difference was not statistically significant $(3.1 \pm 1.4$ vs $4.8 \pm 1.9 \mathrm{~h}$, respec-

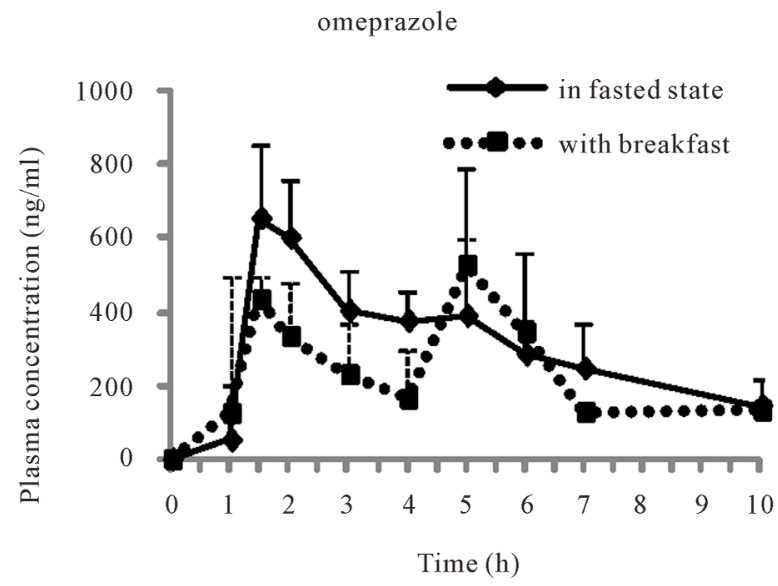

(a) tively; $p=0.061$ ).

The three different genotype groups following the administration of the respective PPI are shown in Table 5. The mean plasma concentration-time curves of rabeprazole in the three different genotype groups are shown in Figure 3. Between the administration of rabeprazole in the fasted state and after breakfast, there were no significant differences in $\mathrm{AUC}_{0-\mathrm{t}}$ in the three CYP2C19 groups. In homo EMs, the Cmax of rabeprazole in the fasted state was significantly higher than that after breakfast $(228.3 \pm$ 65.0 vs $133.8 \pm 53.9 \mathrm{ng} \cdot \mathrm{h} / \mathrm{mL}$, respectively; $\mathrm{p}<0.05$ ). Homo EMs showed a significantly delayed Tmax of rabeprazole after breakfast $(2.4 \pm 0.8$ vs $6.3 \pm 1.0 \mathrm{~h}$, respectively; $p<0.01$ ). The half-life of rabeprazole after breakfast was delayed significantly in PMs $(1.6 \pm 0.5$ vs $3.5 \pm 0.4 \mathrm{~h}$, respectively; $\mathrm{p}<0.05$ ). In hetero EMs and homo EMs, the half-life was not calculable because of the lack of sufficient data.

Regardless of the administration of omeprazole and rabeprazole, PMs demonstrated the highest Cmax and $\mathrm{AUC}_{0-\mathrm{t}}$ after PPI intake under the fasting state and after

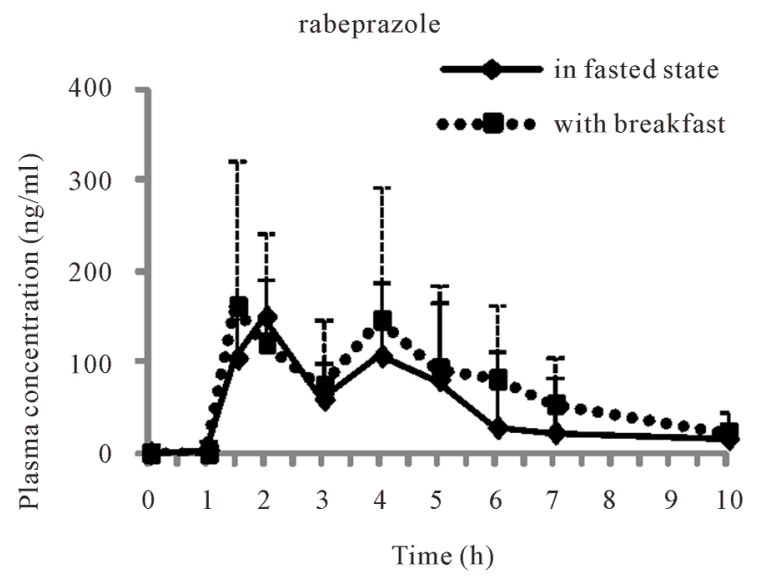

(b)

Figure 1. Mean plasma concentration-time curves of a single dose of $20 \mathrm{mg}$ omeprazole and $10 \mathrm{mg}$ rabeprazole in fastimg state and with breakfast. Each point represents the mean standard \pm deviation.

Table 4. Pharmacokinetic parameters of omeprazole in fasted state and after a meal in the three different CYP2C19 genotypic groups.

\begin{tabular}{|c|c|c|c|c|c|c|c|c|c|}
\hline \multirow{3}{*}{ Parameter } & \multicolumn{9}{|c|}{ Omeprazole } \\
\hline & \multicolumn{2}{|c|}{ Homo EM $(n=4)$} & \multirow[b]{2}{*}{$\mathrm{p}$-value } & \multicolumn{2}{|c|}{ Hetero EM $(n=2)$} & \multirow[b]{2}{*}{$\mathrm{p}$-value } & \multicolumn{2}{|c|}{$\mathrm{PM}(\mathrm{n}=3)$} & \multirow[b]{2}{*}{$\mathrm{p}$-value } \\
\hline & In fasted state & After a meal & & In fasted state & After a meal & & In fasted state & After a meal & \\
\hline $\begin{array}{c}\mathrm{Cmax} \\
(\mathrm{ng} / \mathrm{mL})\end{array}$ & $243.1 \pm 176.6$ & $207.8 \pm 214.3$ & NS & $514.1 \pm 61.3$ & $523.3 \pm 600.5$ & NS & $1333.4 \pm 529.8$ & $1098.8 \pm 551.6$ & NS \\
\hline $\begin{array}{c}\mathrm{AUC}_{0-\mathrm{t}} \\
(\mathrm{ng} \cdot \mathrm{h} / \mathrm{mL})\end{array}$ & $435.0 \pm 294.8$ & $365.2 \pm 341.3$ & NS & $1144.8 \pm 735.6$ & $1130.0 \pm 1368.3$ & NS & $5087.5 \pm 1573.5$ & $3293.1 \pm 1615.8$ & NS \\
\hline $\operatorname{Tmax}(\mathrm{h})$ & $3.1 \pm 1.4$ & $4.8 \pm 1.9$ & 0.06 & $2.5 \pm 0.7$ & $5.0 \pm 0.0$ & NS & $2.8 \pm 1.9$ & $2.7 \pm 2.0$ & NS \\
\hline $\mathrm{t} 1 / 2(\mathrm{~h})$ & $1.3 \pm 0.9$ & $1.0 \pm 0.3$ & NS & $2.0 \pm 1.9$ & $1.0 \pm 0.4$ & NS & $3.6 \pm 1.0$ & $2.3 \pm 0.5$ & NS \\
\hline
\end{tabular}

NS, not significant; data represent mean values \pm standard deviation; Homo EM, homozygous extensive metabolizer; Hetero EM, heterozygous extensive metabolizer; $\mathrm{PM}$, poor metabolizer; Cmax, maximum plasma concentrations, $\mathrm{AUC}_{0-\mathrm{t}}$, the area under the plasma-time concentration curve, Tmax, the time to maximum plasma concentration from time 0 to the time of the last quantifiable concentration, $\mathrm{t} 1 / 2$, half-time. 


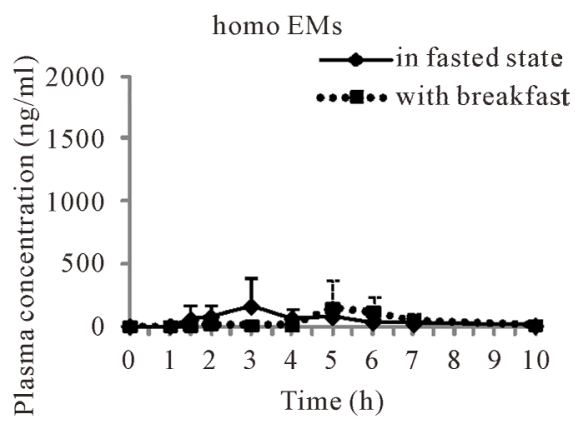

(a)

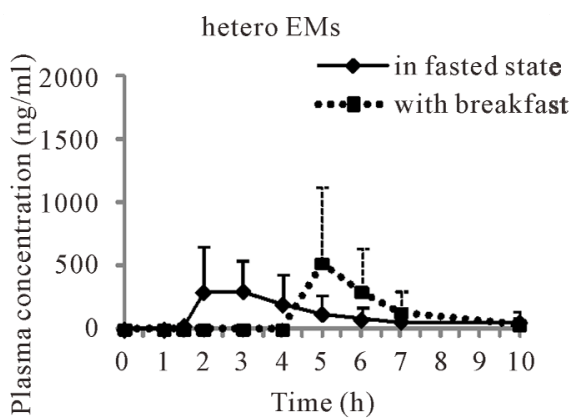

(b)

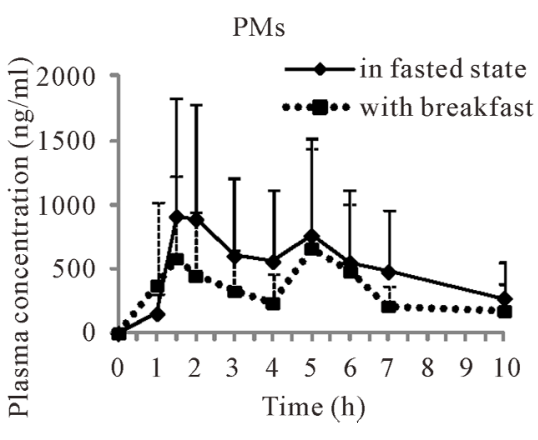

(c)

Figure 2. Mean plasma concentration-time curves of omeprazole in fastimg state and with breakfast in homozygous extensive metabolizers (homo EMs), heterozygous extensive metabolizers (hetero EMs) and poor metabolizers (PMs) classified by CYP2C19 genotype. Each point represents the mean standard \pm deviation.

Table 5. Pharmacokinetic parameters of rabeprazole in fasted state and after a meal in the three different CYP2C19 genotypic groups.

\begin{tabular}{|c|c|c|c|c|c|c|c|c|c|}
\hline \multirow{3}{*}{ Parameter } & \multicolumn{9}{|c|}{ Rabeprazole } \\
\hline & \multicolumn{2}{|c|}{ Homo EM $(n=4)$} & \multirow[b]{2}{*}{ p-value } & \multicolumn{2}{|c|}{ Hetero EM $(n=2)$} & \multirow[b]{2}{*}{ p-value } & \multicolumn{2}{|c|}{$\mathrm{PM}(\mathrm{n}=3)$} & \multirow[b]{2}{*}{ p-value } \\
\hline & In fasted state & After a meal & & In fasted state & After a meal & & In fasted state & After a meal & \\
\hline $\begin{array}{c}\mathrm{Cmax} \\
(\mathrm{ng} / \mathrm{mL})\end{array}$ & $228.3 \pm 65.0$ & $133.8 \pm 53.9$ & $<0.05$ & $215.9 \pm 103.9$ & $121.8 \pm 129.5$ & NS & $344.4 \pm 70.6$ & $307.6 \pm 267.3$ & NS \\
\hline $\begin{array}{c}\mathrm{AUC}_{0-\mathrm{t}} \\
(\mathrm{ng} \cdot \mathrm{h} / \mathrm{mL})\end{array}$ & $366.1 \pm 62.8$ & $320.4 \pm 69.5$ & NS & $427.6 \pm 154.1$ & $344.0 \pm 253.8$ & NS & $872.4 \pm 63.9$ & $785.4 \pm 711.8$ & NS \\
\hline $\operatorname{Tmax}(\mathrm{h})$ & $2.4 \pm 0.8$ & $6.3 \pm 1.0$ & $<0.01$ & $3.0 \pm 1.4$ & $6.0 \pm 0.0$ & NS & $3.3 \pm 1.2$ & $2.8 \pm 1.8$ & NS \\
\hline $\mathrm{t} 1 / 2(\mathrm{~h})$ & $2.0 \pm 2.2$ & $1.1^{\mathrm{a}}$ & - & $0.9 \pm 0.3$ & $5^{\mathrm{a}}$ & - & $1.6 \pm 0.5$ & $3.5 \pm 0.4$ & $<0.05$ \\
\hline
\end{tabular}

NS, not significant; data represent mean values \pm standard deviation; Homo EM, homozygous extensive metabolizer; Hetero EM, heterozygous extensive metabolizer; PM, poor metabolizer; Cmax, maximum plasma concentrations, $\mathrm{AUC}_{0-\mathrm{t}}$, the area under the plasma-time concentration curve, Tmax, the time to maximum plasma concentration from time 0 to the time of the last quantifiable concentration, t1/2, half-time; ${ }^{\mathrm{a} O n e}$ patient; only one patient got enough data for the analysis.

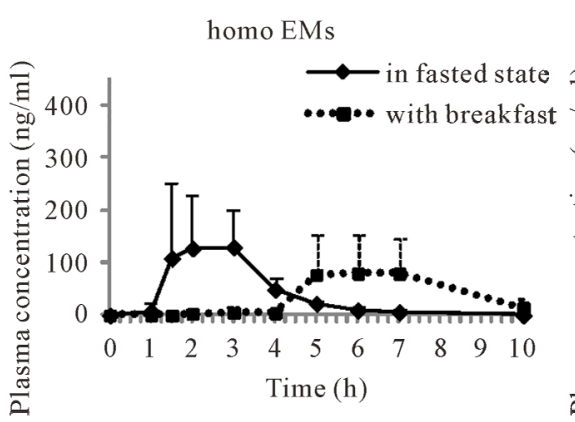

(a)

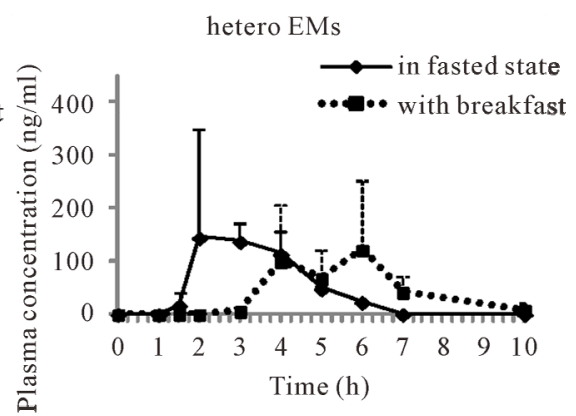

(b)

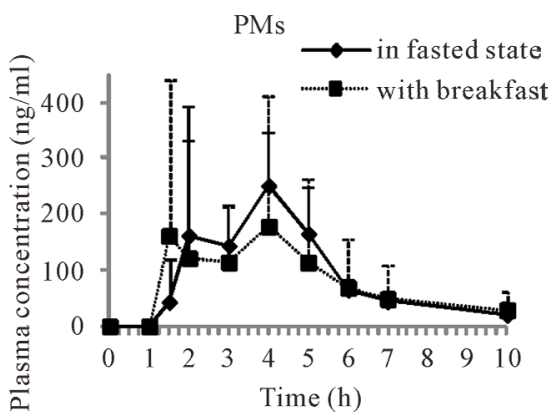

(c)

Figure 3. Mean plasma concentration-time curves of rabeprazole in fastimg state and with breakfast in homozygous extensive metabolizers (homo EMs), heterozygous extensive metabolizers (hetero EMs) and poor metabolizers (PMs) classified by CYP2C19 genotype. Each point represents the mean standard \pm deviation.

breakfast. When administered omeprazole under the fasting state, PMs had significantly higher Cmax and $\mathrm{AUC}_{0-\mathrm{t}}$ values compared with EMs (Cmax; $\mathrm{p}<0.05$, $\mathrm{AUC}_{0-\mathrm{t}} ; \mathrm{p}<0.05$, respectively). With the administration of rabeprazole in the fasted state, $\mathrm{AUC}_{0-\mathrm{t}}$ in $\mathrm{PMs}$ was significantly higher than that in homo EMs $(\mathrm{p}<0.05)$.

\section{Discussion}

In the present study, between the administration of omeprazole or rabeprazole in the fasted state and after breakfast, there were no significant differences in Cmax and $\mathrm{AUC}_{0-\mathrm{t}}$. Meanwhile, the Tmax of rabeprazole after breakfast was significantly longer than that in the fasted state. 
These results were similar to those of previous reports $[23,24]$. Delayed gastric emptying might result in delayed absorption of rabeprazole. It was reported that meals with a high fat content slowed gastric emptying $[28,29]$, and that food, especially a fatty meal, delayed the gastric emptying time of enteric-coated tablets [30].

In the present study, $\mathrm{AUC}_{0 \text {-inf }}$ was calculable in 8 of 9 subjects administered omeprazole after a meal and only in 4 of 9 rabeprazole after a meal because of insufficient data. This may be because the time of the elevation of the plasma rabeprazole concentrations after a meal is delayed more than 10 hours after the administration of a single dose of $10 \mathrm{mg}$ rabeprazole, or rabeprazole absorption was not influenced by the meal. And it could be considered that meal is also influenced by the pharmacokinetics of PPI according to the CYP2C19 genotypes. Therefore, for example, at on-demand therapy, the administration of PPIs after meal should be avoided since before a meal may be more effective than after a meal.

The PPIs are acid-labile substances. Under fed conditions, food delays gastric emptying and PPI degradation increases with increased time in the stomach. It was reported that a considerable interindividual variability in omeprazole bioavailability and suppression of gastric acid secretion exists because of the acid-labile nature of PPIs [31]. Previous studies have revealed a wide interindividual variability in the plasma concentrations of PPIs following the administration of identical doses to different individuals [32]. Interindividual variability in the intragastric $\mathrm{pH}$ influences the dissolution of entericcoated PPIs. As a result, the absorption of PPIs varies among individuals. The buffering effects of meals temporarily raise the intragastric $\mathrm{pH}$, promoting the absorption of PPIs. Since the effect of food may be a balance of all of these factors, it is not possible to know definitively based on the results of this study.

No studies have been reported comparing the influence of a meal on the pharmacokinetics of PPIs among CYP2C19 genotype groups. In the present study, we found that CYP2C19 genotypes could affect the disposition of omeprazole and rabeprazole. When a single dose of $20 \mathrm{mg}$ omeprazole was given in the fasting state, $\mathrm{Cmax}$ and $\mathrm{AUC}_{0-\mathrm{t}}$ in PMs were significantly higher compared with those in homo EMs. With the administration of omeprazole in the fasting state, the relative Cmax value in the homo EMs, hetero EMs and PMs was 1:2.1:5.5; the relative $\mathrm{AUC}_{0-\mathrm{t}}$ value was 1:2.6:11.7, respectively. When a single dose of $10 \mathrm{mg}$ of rabeprazole in the fasting state was administrated, the $\mathrm{AUC}_{0-\mathrm{t}}$ in PMs was significantly higher than that in homo EMs. With the administration of rabeprazole in the fasting state, the relative Cmax value in the homo EMs, hetero EMs and PMs was 1:0.95:1.5; the relative $\mathrm{AUC}_{0-\mathrm{t}}$ value was 1:1.2:2.4, respectively. Because CYP2C19 was deficient in the PM group, the duration of high and sustained plasma concentrations of omeprazole is presumed to be longer in the PM group than in the homo EM group, thereby achieving a stronger and longer inhibition of gastric acid secretion. These results support that rabeprazole was less influenced by CYP2C19 compared with omeprazole, but the pharmacokinetics of rabeprazole was certainly influenced by CYP2C19. Rabeprazole is metabolized to thioether product [33]. This product less effectively suppresses gastric acid than rabeprazole, and is mainly metabolized by CYP2C19 [34]. Because of thioether, rabeprazole seems to be influenced by the genotype of CYP2C19.

In the three CYP2C19 groups, homo EMs may be more likely to be affected by a meal than hetero EMs and PMs.

The proportions of PM, hetero EM, and homo EM individuals in the Caucasian population have been reported to be $2.1 \%, 25.3 \%$ and $72.6 \%$, respectively [35], The proportion of individuals with PMs, hetero EMs and homo EMs in the present study were $33.3 \%, 22.3 \%$, and $44.4 \%$, respectively. The higher percentage of PMs in the present study may have affected the results. With the exception of PMs, the Tmax of omeprazole after a meal was significantly delayed compared with that under the fasting state $(p<0.01)$, and that of rabeprazole after a meal was significantly delayed compared to that under the fasting state $(\mathrm{p}<0.01)$. The Cmax and $\mathrm{AUC}_{0-\mathrm{t}}$ of omeprazole and rabeprazole in homo EMs and hetero EMs were not significantly influenced by a meal (data not shown).

In the present study, intragastric $\mathrm{pH}$ monitoring following the administration of omeprazole or rabeprazole was not undertaken. However, the suppression of gastric acid secretion is related to the AUC of PPIs [21,22]. When a single dose of $10 \mathrm{mg}$ rabeprazole was administered under the fasting state, PMs had the highest mean Cmax, $\mathrm{AUC}_{0-24}$ and intragastric mean $\mathrm{pH}$ among three different CYP2C19 genotypic groups. However, a single dose of not $10 \mathrm{mg}$ but $20 \mathrm{mg}$ rabeprazole was compared among CYP2C19 genotypes. These results slightly differ from those of previous reports $[16,18-20,36]$ in which rabeprazole induced an earlier rise in the intragastric $\mathrm{pH}$ than other PPIs. However, most previous studies examined the effects after the administration of $20 \mathrm{mg}$ rabeprazole or other PPIs on days 3 - 7 [16,18-20,36], not the early postadministration phase $(1-12 \mathrm{~h})$ of a single dose.

\section{Conclusion}

In conclusion, when a single dose of either PPI was administered, the pharmacokinetics of omeprazole was not affected by the meal, whereas the Tmax of rabeprazole 
after the meal was significantly delayed.

\section{Acknowledgements}

This study was funded by Japanese society for Dyspepsia.

\section{REFERENCES}

[1] G. R. Locke 3rd, N. J. Talley, S. L. Fett, A. R. Zinsmeister and L. J. Melton 3rd, "Prevalence and Clinical Spectrum of Gastroesophageal Reflux: A Population-Based Study in Olmsted County, Minnesota," Gastroenterology, Vol. 112, 1997, pp. 1448-1456. doi:10.1016/S0016-5085(97)70025-8

[2] M. Diaz-Rubio, C. Moreno-Elola-Olaso, E. Rey, G. R. Locke 3rd and F. Rodriguez-Artalejo, "Symptoms of Gastro-Oesophageal Reflux: Prevalence, Severity, Duration and Associated Factors in a Spanish Population," Alimentary Pharmacology \& Therapeutics, Vol. 19, No. 1, 2004, pp. 95-105. doi:10.1046/j.1365-2036.2003.01769.x

[3] V. Stanghellini, "Three-Month Prevalence Rates of Gastrointestinal Symptoms and the Influence of Demographic Factors: Results from the Domestic/International Gastroenterology Surveillance Study (DIGEST)," Scandinavian Journal of Gastroenterology, Vol. 34, No. 231, 1999, pp. 20-28. doi:10.1080/003655299750025237

[4] Y. Fujiwara, K. Higuchi, Y. Watanabe, M. Shiba, T. Watanabe, K. Tominaga, N. Oshitani, T. Matsumoto, H. Nishikawa and T. Arakawa, "Prevalence of Gastroesophageal Reflux Disease and Gastroesophageal Reflux Disease Symptoms in Japan," Journal of Gastroenterology and Hepatology, Vol. 20, No. 1, 2005, pp. 26-29. doi:10.1111/j.1440-1746.2004.03521.x

[5] K. Fujimoto, R. Iwakiri, K. Okamoto, K. Oda, A. Tanaka, S. Tsunada, H. Sakata, A. Kikkawa, R. Shimoda, K. Matsunaga, K. Watanabe, B. Wu, S. Nakahara, H. Ootani and A. Ootani, "Characteristics of Gastroesophageal Reflux Disease in Japan: Increased Prevalence in Elderly Women," Journal of Gastroenterology, Vol. 38, Suppl. 15, 2003, pp. 3-6.

[6] S. Ohara, T. Kouzu, T. Kawano and M. Kusano, "Nationwide Epidemiological Survey Regarding Heartburn and Reflux Esophagitis in Japanese," Nippon Shokakibyo Gakkai Zasshi, Vol. 102, No. 8, 2005, pp. 1010-1024.

[7] M. Inamori, J. Togawa, H. Nagase, Y. Abe, T. Umezawa, A. Nakajima, T. Saito, N. Ueno, K. Tanaka, H. Sekihara, H. Kaifu, H. Tsuboi, H. Kayama, S. Tominaga and H. Nagura, "Clinical Characteristics of Japanese Reflux Esophagitis Patients as Determined by Los Angeles Classification," Journal of Gastroenterology and Hepatology, Vol. 18, No. 2, 2003, pp. 172-176. doi:10.1046/j.1440-1746.2003.02932.x

[8] N. J. Bell, D. Burget, C. W. Howden, J. Wilkinson and R. H. Hunt, "Appropriate Acid Suppression for the Management of Gastrooesophageal Reflux Disease," Digestion, Vol. 51, Suppl. 1, 1992, pp. 59-67. doi: $10.1159 / 000200917$
[9] E. Fellenius, T. Berglindh, G. Sachs, et al., "Substituted Benzimidazoles Inhibit Gastric Acid Secretion by Blocking $\left(\mathrm{H}^{++} \mathrm{K}^{+}\right)$ATPase," Nature, Vol. 290, 1981, pp. 159161. doi:10.1038/290159a0

[10] G. Sachs, J. M. Shin, C. Briving, et al., "The Pharmacology of the Gastric Acid Pump: The H+, K+ ATPase," Annual Review of Pharmacology and Toxicology, Vol. 35, 1995, pp. 277-305.

doi:10.1146/annurev.pa.35.040195.001425

[11] T. Andersson, C. G. Regårdh, Y. C. Lou, et al., "Polymorphic Hydroxylation of S-Mephenytoin and Omeprazole Metabolism in Caucasian and Chinese Subjects," Pharmacogenetics, Vol. 2, 1992, pp. 25-31. doi:10.1097/00008571-199202000-00005

[12] M. Chang, G. Tybring, M. L. Dahl, et al., "Interphenotype Differences in Disposition and Effect on Gastrin Levels of Omeprazole-Suitability of Omeprazole as a Probe for CYP2C19," British Journal of Clinical Pharmacology, Vol. 39, No. 5, 1995, pp. 511-518. doi:10.1111/j.1365-2125.1995.tb04488.x

[13] T. Furuta, K. Ohashi, K. Kosuge, et al., "CYP2C19 Genotype Status and Effect of Omeprazole on Intragastric pH in Humans," Clinical Pharmacology \& Therapeutics, Vol. 65, No. 5, 1999, pp. 552-561. doi:10.1016/S0009-9236(99)70075-5

[14] T. Andersson, J. O. Miners, M. E. Veronese, et al., "Identification of Human Liver Cytochrome P450 Isoforms Mediating Secondary Omeprazole Metabolism," British Journal of Clinical Pharmacology, Vol. 37, No. 6, 1994, pp. 597-604. doi:10.1111/j.1365-2125.1994.tb04310.x

[15] L. Pichard, G. Gillet, C. Bonfils, et al., "Oxidative Metabolism of Zolpidem by Human Liver Cytochrome P450S," Drug Metabolism and Disposition, Vol. 23, No. 11, 1995, pp. 1253-1262.

[16] K. Adachi, T. Katsube, A. Kawamura, et al., "CYP2C19 Genotype Status and Intragastric pH during Dosing with Lansoprazole or Rabeprazole," Alimentary Pharmacology \& Therapeutics, Vol. 14, No. 10, 2000, pp. 1259-1266. doi:10.1046/j.1365-2036.2000.00840.x

[17] Y. Horai, M. Kimura, H. Furuie, K. Matsuguma, S. Irie, Y. Koga, T. Nagahama, M. Murakami, T. Matsui, T. Yao, A. Urae and T. Ishizaki, "Pharmacodynamic Effects and Kinetic Disposition of Rabeprazole in Relation to CYP2C19 Genotypes," Alimentary Pharmacology \& Therapeutics, Vol. 15, No. 6, 2001, pp. 793-803. doi:10.1046/j.1365-2036.2001.00980.x

[18] N. Shirai, T. Furuta, Y. Moriyama, H. Okochi, K. Kobayashi, M. Takashima, F. Xiao, K. Kosuge, K. Nakagawa, H. Hanai, K. Chiba, K. Ohashi and T. Ishizaki, "Effects of CYP2C19 Genotypic Differences in the Metabolism of Omeprazole and Rabeprazole on Intragastric $\mathrm{pH}$," Alimentary Pharmacology \& Therapeutics, Vol. 15, No. 12, 2001, pp. 1929-1937. doi:10.1046/j.1365-2036.2001.01108.x

[19] T. Saitoh, Y. Fukushima, H. Otsuka, J. Hirakawa, H. Mori, T. Asano, T. Ishikawa, T. Katsube, K. Ogawa and S. Ohkawa, "Effects of Rabeprazole, Lansoprazole and Omeprazole on Intragastric $\mathrm{pH}$ in CYP2C19 Extensive 
Metabolizers," Alimentary Pharmacology \& Therapeutics, Vol. 16, No. 10, 2002, pp. 1811-1817. doi:10.1046/j.1365-2036.2002.01348.x

[20] T. Shimatani, M. Inoue, T. Kuroiwa, J. Xu, H. Mieno, M. Nakamura and S. Tazuma, "Acid-Suppressive Effects of Rabeprazole, Omeprazole, and Lansoprazole at Reduced and Standard Doses: A Crossover Comparative Study in Homozygous Extensive Metabolizers of Cytochrome P450 2C19," Clinical Pharmacology \& Therapeutics, Vol. 79, No. 1, 2006, pp. 144-152. doi:10.1016/j.clpt.2005.09.012

[21] M. Kanemaru, M. Nakashima, T. Kajiho, Y. Matsuda and T. Oka, "Inhibition of Gastric Secretion by Omeprazole, a Proton Pump Inhibitor-Effect on Basal and TetragastrinStimulated Gastric Secretions in Healthy Volunteers," Rinsyoiyaku, Vol. 5, No. 1, 1989, pp. 13-28.

[22] T. Lind, C. Cederberg, G. Ekenved, U. Haglund and L. Olbe, "Effect of Omeprazole-A Gastric Proton Pump Inhibitor-On Pentagastrin Stimulated Acid Secretion in Man,” Gut, Vol. 24, No. 4, 1983, pp. 270-276. doi:10.1136/gut.24.4.270

[23] M. Nakashima, M. Kanemaru, H. Hashimoto, Y. Takiguchi, A. Mizuno, T. Kajiho, T. Oka and Y. Matsuda, "Phase I Study of Omeprazole-Single-Dose and MultipleDose Studies," Japanese Journal of Clinical Pharmacology and Therapeutics, Vol. 19, No. 4, 1988, pp. 667-679.

[24] S. Yasuda, A. Ohnisi, T. Ogawa, Y. Tomono, J. Hasegawa, H. Nakai, Y. Shimamura and N. Morishita, "Pharmacokinetic Properties of E3810, a New Proton Pump Inhibitor, in Healthy Male Volunteers," International Journal of Clinical Pharmacology and Therapeutics, Vol. 32, No. 9, 1994, pp. 466-473.

[25] M. Bannai, K. Higuchi, T. Akesaka, et al., "Single-Nucleotide-Polymorphism Genotyping for Whole-GenomeAmplified Samples Using Automated Fluorescence Correlation Spectroscopy," Analytical Biochemistry, Vol. 327, No. 2, 2004, pp. 215-221.

[26] C. H. Oliveira, R. E. Barrientos-Astigarraga, E. Abib, G. D. Mendes, D. R. da Silva and G. de Nucci, "Lansoprazole Quantification in Human Plasma by Liquid Chromatography-Electrospray Tandem Mass Spectrometry," Journal of Chromatography B, Vol. 783, No. 2, 2003, pp. 453-459. doi:10.1016/S1570-0232(02)00711-0

[27] J. Huang, Y. Xu, S. Gao, L. Rui and Q. Guo, "Development of a Liquid Chromatography/Tandem Mass Spectrometry Assay for the Quantification of Rabeprazole in Human Plasma," Rapid Communications in Mass Spectrometry, Vol. 19, No. 16, 2005, pp. 2321-2324. doi: $10.1002 / \mathrm{rcm} .2066$

[28] L. Z. Benet, D. L. Kroetz and L. B. Sheiner, "Pharmacokinetics: The Dynamics of Drug Absorption, Distribution, and Elimination,” In: J. G. Hardman, L. E. Limbird,
P. B. Molinoff, R. W. Ruddon and A. G. Gilman, Eds., Goodman and Gilman's: The Pharmacolgical Basis of Therapeutics, 9th Edition, Mcgraw-Hill, New York, 1996, pp. 3-28.

[29] E. A. Mayer, "The Physiology of Gastric Storage and Emptying," In: L. R. Johnson, D. H. Alpers, E. D. Jacobson, J. Christensen and J. H. Walsh, Eds., Physiology of the Gastrointestinal, 3rd Edition, Raven Press, New York, 1994, pp. 929-976.

[30] K. Ewe, A. G. Press, S. Bollen and I. Schuhn, "Gastric Emptying of Indigestible Tablets in Relation to Composition and Time of Ingestion of Meals Studied by Metal Detector," Digestive Diseases and Sciences, Vol. 36, No. 2, 1991, pp. 146-152. doi:10.1007/BF01300748

[31] C. Larson, N. J. Cavuto, D. A. Flockhart and R. B. Weinberg, "Bioavailability and Efficacy of Omeprazole Given Orally and by Nasogastric Tube," Digestive Diseases and Sciences, Vol. 41, No. 3, 1996, pp. 475-479.

[32] T. Furuta, N. Shirai, M. Sugimoto, A. Nakamura, A. Hishida and T. Ishizaki, "Influence of CYP2C19 Pharmacogenetic Polymorphism on Proton Pump InhibitorBased Therapies," Drug Metabolism and Pharmacokinetics, Vol. 20, No. 3, 2005, pp. 153-167. doi: $10.2133 / \mathrm{dmpk} .20 .153$

[33] S. Yasuda, A. Ohnishi, T. Ogawa, Y. Tomono, et al., "Pharmacokinetic Properties of E3810, a New Proton Pump Inhibitor in Healthy Male Volunteers," International Journal of Clinical Pharmacology and Therapeutics, Vol. 32, No. 9, 1994, pp. 466-473.

[34] X. Q. Li, T. B. Andersson, M. Ahlstrom and L. Weidolf, "Comparison of Inhibitory Effects of the Proton Pump Inhibiting Drugs Omeprazole, Esomeprazole, Lansoprazole, Pantoprazole, and Rabeprazole on Human Cytochrome P450 Activities," Drug Metabolism and Disposition, Vol. 32, No. 8, 2004, pp. 821-827.

doi: $10.1124 / \mathrm{dmd} \cdot 32.8 .821$

[35] H. G. Xie, C. M. Stein, R. B. Kim, G. R. Wilkinson, D. A. Flockhart and A. J. Wood, "Allelic, Genotypic and Phenotypic Distributions of S-Mephenytoin 4'-Hydroxylase (CYP2C19) in Healthy Caucasian Populations of European Descent Throughout the World," Pharmacogenetics, Vol. 9, No. 5, 1999, pp. 539-549. doi:10.1097/00008571-199910000-00001

[36] M. P. Williams, J. Sercombe, M. I. Hamilton and R. E. Pounder, "A Placebo-Controlled Trial to Assess the Effects of 8 Days of Dosing with Rabeprazole versus Omeprazole on 24-h Intragastric Acidity and Plasma Gastrin Concentrations in Young Healthy Male Subjects," Alimentary Pharmacology \& Therapeutics, Vol. 12, No. 11, 1998, pp. 1079-1089. doi:10.1046/j.1365-2036.1998.00418.x 